Revue

Revue de l'histoire des religions

de Ihistoire des religions

Sylvie ABALLÉA et Frédéric ElSIG (dir.), L'image des saints dans les Alpes occidentales à la fin du Moyen Âge

Rome, Viella, (« I libri di Viella. Arte »), 2015

\title{
Marie Lezowski
}

\section{(2) OpenEdition}

\section{Journals}

Édition électronique

URL : http://journals.openedition.org/rhr/8784

DOI : ERREUR PDO dans /localdata/www-bin/Core/Core/Db/Db.class.php L.34 : SQLSTATE[HY000]

[2006] MySQL server has gone away

ISSN : 2105-2573

Éditeur

Armand Colin

Édition imprimée

Date de publication : 1 septembre 2017

Pagination : 553-555

ISBN : 978-2-200-93127-8

ISSN : 0035-1423

\section{Référence électronique}

Marie Lezowski, « Sylvie Aballéa et Frédéric Elsig (dir.), L'ímage des saints dans les Alpes occidentales à la fin du Moyen Âge », Revue de l'histoire des religions [En ligne], 3 | 2017, mis en ligne le 01 septembre 2017, consulté le 08 janvier 2021. URL : http://journals.openedition.org/rhr/8784 ; DOI : https:// doi.org/10.4000/rhr.8784

Ce document a été généré automatiquement le 8 janvier 2021

Tous droits réservés 


\title{
Sylvie ABALLÉA et Frédéric ELSIG (dir.), L'image des saints dans les Alpes occidentales à la fin du Moyen Âge
}

Rome, Viella, (« I libri di Viella. Arte »), 2015

\author{
Marie Lezowski
}

\section{RÉFÉRENCE}

Sylvie ABALLÉA et Frédéric ELSIG (dir.), L’image des saints dans les Alpes occidentales à la fin $d u$ Moyen Âge, Rome, Viella, (« I libri di Viella. Arte »), 2015, 24 cm, 230 p., $35 €$, ISBN 978-88-6728-353-8.

1 Une conjoncture patrimoniale et touristique commande la parution de cet ouvrage dans la belle collection des livres d'art de Viella. En 2013, six expositions dédiées à l'iconographie des saints dans le duché de Savoie médiéval se sont tenues simultanément à Annecy, Aoste, Suse, Sion et Genève. Un colloque a été conçu en parallèle de la rédaction du catalogue commun, intitulé Des Saints et des hommes (dir. par Simone Baiocco et Marie Claude Morand, Milan, Officina Libraria, 2013), après diverses actions de sauvegarde de la statuaire médiévale alpine. Le présent livre, issu du colloque, n'est pas d'un abord aisé, car il dépend souvent de ce catalogue : plusieurs contributions prennent la forme de compléments érudits à ses notices. Idéalement, il faut pouvoir les consulter en parallèle des actes du colloque.

2 En dépit de cette réserve importante, le livre se signale à l'attention des historiens et des historiens de l'art par son thème ambitieux : le rapport entre l'essor d'un culte et un territoire donné. Peut-on parler de "saints alpins» et, dans ce cas, quelles en seraient les particularités? En dédiant le livre à la mémoire de l'historien de l'art Enrico Castelnuovo, grand spécialiste des circulations transalpines, Sylvie Aballéa et Frédéric Elsig se dégagent d'emblée du vieux postulat, issu de l'hagiographie, de l'identité parfaite entre le saint et le lieu sacralisé par sa présence. Et pourtant, l'unité 
du recueil, soulignée par son titre, est bien donnée par une région. Dans leur diversité, les études de cas ont pour hypothèse commune l'identification du saint par le lieu, et inversement. Tout l'intérêt est de suivre le cheminement emprunté par les contributeurs, historiens, historiens de l'art et conservateurs, pour confirmer ou infirmer cette spécificité savoyarde.

Pour ce faire, les auteurs ont recours à une iconographie d'une grande variété, produite du XIII ${ }^{e}$ au XVI ${ }^{e}$ siècle, et surtout au Xv ${ }^{e}$ siècle. En plus de la statuaire, au centre de nombreuses contributions, ils s'appuient sur des miniatures, des peintures (fresques et retables), des pièces d'orfèvrerie et des sceaux. Leur propos est de mettre en miroir dévotions et art, ou encore "pratiques dévotionnelles» et "spécificités iconographiques", pour reprendre les titres des deux premières parties. Les cultes locaux, attestés par exemple par des fondations et par des sources hagiographiques, sont rapprochés de types figurés propres à la région. Parmi les dévots, les princes de Savoie se taillent la part du lion : ce sont aussi les principaux commanditaires, comme il apparaît clairement dans la troisième partie («Territoire et politique »). Les ducs savoyards, princes chevaliers, longtemps rétifs aux usages politiques de la sainteté, deviennent, à partir du règne d'Amédée VIII (1391-1451), les champions d'une dévotion ostentatoire et se laissent gagner par la tentation de la beata stirps. Laurent Ripart montre très clairement ce basculement. Évoquée plus rapidement dans le quatrième et dernier temps du livre (" Transformations du système »), l'apparition des Réformes ne met pas fin à cette ferveur, même si elle donne lieu à des destructions et à des transferts d'images. Trois contributions nuancent les effets de l'iconoclasme réformé, en présentant quelques exemples de remplois.

4 À la question délicate des liens entre le culte et le lieu, l'ouvrage apporte deux réponses principales, sur lesquelles je souhaiterais m'arrêter à présent. La commande d'effigies, princière ou élitaire, est le premier facteur, décisif, de localisation des dévotions. Dans la partie dédiée aux "pratiques dévotionnelles", Sandrine Boisset Thermes, Laurence Ciavaldini Rivière et Brigitte Roux étudient des images sculptées ou peintes en miniature, afin d'identifier, de manière croisée, les saints figurés et les commanditaires, surtout à partir d'attributs traditionnels, de symboles héraldiques et de critères stylistiques. Selon cette méthode, L. Ciavaldini Rivière attribue la commande d'un rouleau de prières (Sens, Bibl. mun., ms. 39) à Janus de Savoie (1440-1491), époux d'Hélène de Luxembourg. Au côté des princes de Savoie, d'autres commanditaires émergent. En concentrant sa recherche sur la statuaire de Chambéry au $\mathrm{Xv}^{\mathrm{e}}$ siècle, au moment où le centre de gravité du duché se déplace vers Turin, $\mathrm{S}$. Boisset Thermes met en évidence le rôle du clergé du décanat, très attentif à la qualité des images, des notables locaux et des corporations de métier. Le grand profit de cette lecture iconographique est qu'elle ne valide pas toujours l'idée initiale d'un particularisme savoyard. Dans sa lecture des miniatures des Heures de Louis de Savoie (Paris, BnF, lat. 9473), B. Roux conclut à l'absence de choix marqué dans les saints représentés. Cette indifférence au contexte régional, en apparence décevante, témoigne de l'ambition politique de Louis de Savoie, qui entend s'élever au rang des ducs de Berry et de Bourgogne.

5 Pour caractériser le rapport des dévotions ducales avec la Savoie, il faut distinguer en fait entre les supports de l'image. Autant la miniature est propice à la représentation de cultes indépendants du contexte régional, autant les images d'église, offertes à la dévotion collective, balisent les États sur lequel les ducs établissent leur emprise de 
plus en plus fermement à la fin du Moyen Âge. Comme le montre la troisième partie du livre, avant la " géographie céleste » des XVI ${ }^{\mathrm{e}}$ et XVII ${ }^{\mathrm{e}}$ siècles, étudiée par Paolo Cozzo, les ducs de Savoie placent dès le XIV ${ }^{e}$ siècle leur maison et leurs États sous la protection d'intercesseurs privilégiés et ils en multiplient les représentations peintes et sculptées. Ce sont avant tout les figures traditionnelles de la Vierge et de saint Georges, éclipsé par saint Maurice à partir $d u \mathrm{Xv}^{\mathrm{e}}$ siècle (L. Ripart). L'analyse iconographique révèle aussi des figures moins renommées de la cour céleste et directement inscrites dans la géographie savoyarde. Par exemple, l'éclosion du culte de Nicolas de Tolentin en Savoie ne s'expliquerait guère sans la fondation, en 1505, d'un monastère augustinien à Brou, près de Bourg-en-Bresse, que Marguerite d'Autriche dédie à la mémoire de son défunt époux Philibert le Beau (M. Briat-Philippe). Ces saints politiques ne servent pas tous le renforcement du pouvoir ducal. Patrick Elsig observe les rapports entre l'image sacrée et le pouvoir de l'évêque à propos du cas de Théodule/Théodore, évêque fondateur de l'Église de Sion. Ce contemporain d'Ambroise de Milan reçoit l'attribut du glaive au début $d u \mathrm{xv}^{\mathrm{e}}$ siècle, alors même que l'évêché lutte pour la défense de ses droits temporels sur le Valais. Malgré sa concision, la troisième partie fait bien apparaître les strates du territoire (princière, féodale et ecclésiastique) à prendre en compte pour étudier l'émergence ou le renforcement d'un culte en Savoie.

6 Le second critère de compréhension du particularisme savoyard, sans être analysé à part, est évoqué dans presque toutes les contributions. C'est la rudesse des conditions de vie dans les vallées alpines, qui vient colorer les pouvoirs miraculeux des saints locaux: Théodule protège les récoltes, Bernard d'Aoste (ou de Menthon) favorise le passage des cols. Même quand les images sont commandées par des princes, l'exégèse iconographique implique un retour sur le fond des croyances collectives : les légendes des saints vainqueurs des intempéries et des «diables» des montagnes leur donnent leurs attributs distinctifs. Dans la deuxième partie du recueil, Vittorio Natale, Manuele Berardo et Luca Jaccod s'arrêtent en détail sur les représentations de Bernard d'Aoste, d'Antoine abbé et de Grat d'Aoste au cours des siècles. Parmi les enseignements de ces pages, retenons la présence en image des différentes strates sociales du culte. Ainsi de Grat, évêque d'Aoste et inventeur présumé du chef de Jean-Baptiste : figuré avec une relique prestigieuse et sous un nuage menaçant, le saint évêque est invoqué par les autorités épiscopales et ducales, mais aussi par tout un chacun, parce qu'il peut dissiper la tempête (L. Jaccod). De même, Théodule doit son succès à ses pouvoirs sur le climat, autant qu'à sa pugnacité légendaire face à Charlemagne (P. Elsig).

7 Ces études de cas, à confronter aux notices du catalogue Des Saints et des hommes, offrent l'apport le plus remarquable du livre. Elles montrent comment une même figure de sainteté, souvent peu caractérisée à l'origine, réunit à la fin du Moyen Âge les traits de l'homme de pouvoir et du protecteur face aux incertitudes quotidiennes de la montagne. Le sanctoral savoyard ainsi caractérisé est peu enclin au changement : il évolue plus volontiers par la juxtaposition que par l'apparition de nouveaux intercesseurs. La préservation des images au temps de la Réforme vient confirmer le conservatisme observé au $\mathrm{XV}^{\mathrm{e}}$ siècle. En somme, sans tambour ni trompette, l'iconographie propose une relecture convaincante de la sainteté "populaire " de Savoie, jadis étudiée par Arnold Van Gennep selon la méthode ethnographique. 


\section{AUTEURS}

\section{MARIE LEZOWSKI}

Université d'Angers - Centre de recherches historiques de l'Ouest. 